\title{
Are We Free to Imagine What We Choose?
}

\author{
Daniel Munro and Margot Strohminger \\ Penultimate draft; please cite version published in Synthese
}

\begin{abstract}
It has long been recognized that we have a great deal of freedom to imagine what we choose. This paper explores a thesis - what we call "intentionalism (about the imagination)"- that provides a way of making this evident (if vague) truism precise. According to intentionalism, the contents of your imaginings are simply determined by whatever contents you intend to imagine. Thus, for example, when you visualize a building and intend it to be of King's College rather than a replica of the college you have imagined the former rather than the latter because you intended to imagine King's College. This is so even if the visual image you conjure up equally resembles either. This paper proposes two kinds of counterexamples to intentionalism and discusses their significance. In particular, it sketches a positive account of how many sensory imaginings get to be about what they are about, which explains how the causal history of our mental imagery can prevent us from succeeding in imagining what we intended.
\end{abstract}

Keywords. Imagination; mental imagery; visualization; sensory imagination; intentions to imagine.

A longstanding question in the philosophy of imagination asks how imaginings get to be about what they are about. Suppose that you imagine King's College (or whatever your favorite building is) on fire. We can then ask what makes your imagining about that building rather than something else. One popular response to this question appeals simply to the fact that King's College is what you intended to imagine. It says that your imaginings are about whatever you intend them to be about. Call this response intentionalism (about the imagination).

Intentionalism provides a way of making precise the truism that we have a great deal of freedom to imagine what we choose. We are free to imagine what we choose because we can imagine something simply by acting on an intention to imagine that thing, or so the intentionalist maintains. It is therefore unsurprising to see intentionalism feature as a common assumption in recent work in the philosophy of imagination, typically with very little said in its defense. ${ }^{1}$

But, as with so many views that are simply assumed with little argument in their favor, intentionalism is false, or so we aim to show in this paper. Here is the paper's plan. Section 1 considers how to state intentionalism and revisits the two main motivations for it in the

\footnotetext{
${ }^{1}$ Intentionalism traces back at least to Wittgenstein 1980. For endorsement in the contemporary debate, see Fodor 1975, Noordhof 2002, McGinn 2004, Dorsch 2012, Langland-Hassan 2016, Balcerak Jackson 2018, and Kind 2019.
} 
literature. There we suggest that intentionalism is best understood as a view about imaginings that involve mental imagery, which result from intentions to imagine. Section 2 then proposes counterexamples to intentionalism in which someone acts on an intention to imagine one object yet imagines a distinct object instead. Section 3 then explains how our counterexamples also spell trouble for a view that is sometimes used to motivate intentionalism: namely, that one cannot be mistaken about what one is imagining. Section 4 then sketches an alternative theory about the content of sensory imagination. Unlike intentionalism, it assigns a role to the causal history of mental imagery as well as intentions to imagine. Section 5 anticipates and replies to objections.

\section{Intentionalism about the imagination}

Intentionalism says that when you imagine some content as a result of an intention to imagine something, this is because you intended to imagine that same content. In other words, whenever you intend to imagine something and act on that intention, the content of your intention about what to imagine determines the content you imagine. Thus for example suppose someone $S$ imagines something as a result of an intention to imagine $N$ (where " $N$ " is a proper name for an object). According to the intentionalist, $S$ thereby succeeds in imagining $N .^{2}$

Intentionalism does not tell us about how all imaginings get their content. Most obviously, intentionalism must be restricted to imaginings that result from intentions to imagine something. Arguably many imaginings do not result from such intentions but are completely involuntary. Consider someone whose mind involuntarily wanders to King's College while they are absent-mindedly daydreaming about their upcoming trip to Cambridge. This subject arguably imagines King's College even though she has no intention to do so. And it is plausible that the same applies to someone who produces a mental image of King's College while asleep and dreaming: they too unintentionally imagine King's College. ${ }^{3}$ Intentionalism

\footnotetext{
${ }^{2}$ We use proper names here only to help illustrate the view. Intentionalism also predicts that a subject will succeed in imagining the $F$ (likewise an $F$ ) when $S$ imagines something as a result of imagining the $F$ (or an $F$ ), where $F$ is a description of an object. As we discuss at the end of Sect. 2, problems arise for intentionalism regardless of how we refer to the objects subjects intend to imagine.

${ }^{3}$ For recent discussions that claim that imagining features in mind-wandering and dreaming, see Irving 2016 and Ichikawa 2009 respectively.
} 
does not apply to these cases. ${ }^{4}$ That said we can construe the intentions to imagine here in a sense broad enough to include Searle's (1983: ch. 3) "intentions in action", which stand in contrast to "prospective" intentions that are planned in advance. As a result, subjects can intentionally imagine King's College even when they don't deliberately intend to imagine it before their imagining. ${ }^{5}$

Intentionalism should also be understood as a view about sensory imaginings, or imaginings that involve the production of mental imagery, in particular. ${ }^{6}$ The focus on sensory imagination traces back to Wittgenstein. ${ }^{7}$ His posthumously published Remarks on the Philosophy of Psychology include the following remark:

Image and intention. Forming an image can also be compared to creating a picture in this way-namely, I am not imagining whoever is like my image; no, I am imagining whoever it is I mean to imagine (1980: §115).

\footnotetext{
${ }^{4}$ Intentionalists do not always make this restriction to intentional imaginings explicit (perhaps because they are thinking of imagining as necessarily intentional, as in Dorsch 2012: ch. 13). However Langland-Hassan (2016: 63) and Balcerak Jackson (2018: 212) are explicit on this point.

5 The notion of intention in action characterizes actions that are not merely accidental or reflexive even though they are not planned in advance. As an example consider how, after sitting down at your computer, you might proceed to type in a password, click on an unread email notification, and read the email. Each step in this sequence can be something you do intentionally, while at the same time feeling quite automatic and not involving a prior, explicit intention or plan to execute each step. As Langland-Hassan (2016: 62-3) notes, imaginings are plausibly often intentional in this minimal sense.

${ }^{6}$ How exactly to understand sensory imagination and its relationship to imagination is a delicate matter. Indeed, it's not even clear that sensory imagining is a single attitude. According to the dominant "simulationist" framework, the imagination is a capacity to re-create or simulate other mental states (see especially Currie and Ravenscroft 2002). There are at least two kinds of sensory imaginings within this framework: states that simulate sensory experiences and states that simulate beliefs while also having mental imagery as constituents. (More generally, discussions of imagination sometimes distinguish propositional imagination from something purely imagistic and argue that the former can contain imagery as constituents - see especially Van Leeuwen 2014: 799 and Langland-Hassan 2020: ch. 3.) Fortunately for us we do not need to rely on a developed theory of (sensory) imagination in this paper as long as the counterexamples to intentionalism we pose below are clear cases of sensory imagination regardless of the theory one adopts. We think this is true of our counterexamples.

${ }^{7}$ For discussion see White 1990: §B. Writing about the period spanning Sartre, Wittgenstein and Ryle, White writes: "The important question...is what makes an image of something an image of it. It is not its resemblance, since my image, like my painting, of my friend Peter need not look any different from my image, or my painting, of his twin brother. To be an image is not to be a copy. My image is of what I intended it to be of. Did I intend it to be of Peter or of his twin?" (1990: 49).
} 
In the contemporary debate we find several authors endorsing essentially the same idea as Wittgenstein. Fodor and McGinn are two prominent early examples: ${ }^{8}$

Suppose that what one visualizes in imaging a tiger might be anything from a fullscale tiger portrait... to a sort of transient stick figure (in the case of poor imagers like me). What makes my stick figure an image of a tiger is not that it looks much like one (my drawings of tigers don't look much like tigers either) but rather that it's my image, so I'm the one who gets to say what it's an image of. My images (and my drawings) connect with my intentions in a certain way; I take them as tiger-pictures for purposes of whatever task I have in mind. (Fodor 1975: 191) ${ }^{9}$

[T] he identity of my imagined object is fixed by my imaginative intentions... The identity of the object is epistemically prior to its appearance in the image: the imaginer starts with the object and then constructs an image of it. He does not have to figure out the identity of the object from the way his image represents it... I know that my image is of my mother because I intended it to be; I don't have to consult the appearance of the person in the image and then infer that I must have formed an image of my mother. (McGinn 2004: 31)

We will adopt this same focus and assume that intentionalism is a view specifically about sensory imagination. ${ }^{10}$

Because intentionalism is often taken to be intuitively plausible or even obvious, we find only weak motivations for it in the literature. One motivation derives from the apparent failure of a competing "resemblance-based" story about how sensory imaginings get their contents. According to this competing story, an imagining is of something because the image accompanying it resembles that object. That can't be right if, as seems plausible, one can use

\footnotetext{
${ }^{8}$ See also Noordhof 2002: 430-1, Dorsch 2012: 106, Langland-Hassan 2016: 61-2, Balcerak Jackson 2018: 212-4, and Kind 2019: 167. Langland-Hassan 2016 is the only exception to the rule that we have found: he explicitly applies intentionalism to both sensory imaginings and non-sensory "propositional imaginings."

${ }^{9}$ As Fodor's usage of the term "imaging" indicates, he is interested in several kinds of states involving mental imagery. However since he includes imagining among these states (1975: 181), it is clear that he is an intentionalist in our sense.

${ }^{10}$ Intentionalists typically use examples of visual imagery, but we assume that they intend their claims to extend to imagining in any sensory modality. After all none of the authors explicitly restrict their claims just to visual imagery and what motivations they do give for the view generalize straightforwardly to imagination in other sensory modalities.
} 
the same visual image to imagine different objects, say, King's College or a replica of the college. ${ }^{11}$ Indeed when this happens, it seems plausible that what makes it the case that you have imagined King's College as opposed to the replica is that you intended to imagine King's College. Thus perhaps more generally what matters for content-determination is not resemblance at all but rather the content of one's intention about what to imagine. This motivation for intentionalism is obviously very weak: the failure of the resemblance-based account does not force upon us the intentionalist alternative even if it looks well-suited to accommodate cases for which the resemblance-based account fails. It could instead be that, for example, several factors explain how imaginings get to be what they are about, where the content of one's intention is just one factor.

A second line of argument that is sometimes used to motivate intentionalism appeals to another widespread assumption about the imagination: that one cannot be mistaken about what one is imagining. The guiding idea behind this argument is that intentionalism helps us to explain this assumption. Of course this argument can only succeed if this assumption is true. We will argue in Section 3 that it is false; in fact the same sorts of cases that undermine intentionalism also undermine the thesis that one cannot be mistaken about what one is imagining. Thus this line of reasoning provides no support for intentionalism. First though Section 2 will argue against intentionalism directly.

\section{Counterexamples to intentionalism}

This section presents two types of counterexamples to intentionalism, which we'll call "bad introduction" and "bad memory" cases. These cases show that it is possible for someone to imagine one thing even though they were acting on an intention to imagine something else instead.

We begin with an example of a bad introduction case:

College Introduction. You're visiting Cambridge for the first time, and a friend is showing you around. She points to a certain college and says, "That's King's College."

\footnotetext{
${ }^{11}$ This is sometimes called the "Multiple Use Thesis" following Noordhof (2002: 428). Fodor (1975: 181) and Dorsch (2012: 94) appeal to it in motivating intentionalism.
} 
In fact, the college she was pointing to was Trinity College. From this experience, you store an image in memory that exactly resembles Trinity College, which you take to be a memory of King's College. Later, you form an intention to imagine King's College on fire and act on that intention. Your mental image resembles Trinity College, and its causal history traces back to the experience in which your friend introduced Trinity College to you as King's, via your memory from that experience.

Intuitively, you have failed to imagine King's College in this case because what you really imagined is Trinity College. It seems clear that you're imagining the same object which your friend introduced to you while showing you around Cambridge, given the way your mental image causally traces back to that experience. Furthermore, if your friend were later to take you back to Cambridge and ask you to point out the college which you had been imagining on fire, you would be correct to point to Trinity College rather than to King's. So, although you intended to imagine King's College, you ended up only imagining Trinity College. This case shows that the tight link which intentionalism posits between the contents of imagination and of imaginative intentions fails to hold: it's possible to imagine $N$ despite the fact that one is acting on an intention to imagine $N^{\prime}$ rather than $N$.

Bad memory cases also work as counterexamples to intentionalism. Consider this case: College Memory. You're a tourist exploring Cambridge alone. You come across King's College and accurately match it up with the label "King's College" on your map. You then do the same with Trinity College and retain memories of both colleges. Later, when reflecting upon memories from your trip to Cambridge, you get the two memories mixed up: you associate the image of King's College with the label "Trinity College" and vice versa. You then form an intention to imagine King's College on fire and act on that intention. Your mental image resembles Trinity College, and its causal history traces back to the experience in which you saw Trinity College and identified it as such using your map.

Just as in College Introduction, intuitively you have failed to imagine King's College in this case because what you really imagined is Trinity College. It seems clear that you're imagining the object which you originally correctly identified as Trinity College, given the way your mental image causally traces back to your experience of Trinity. Furthermore, if you were to 
later go back to Cambridge and realize that you had mistakenly "swapped the labels" on your memory images, you would be right to say, "I got the two mixed up - the memory I thought of as being about King's College was really about Trinity College." So, although you intended to imagine King's College, you ended up imagining Trinity College instead. This is contrary to intentionalism, which says that acting on an intention to imagine $N$ implies that one imagines $N .^{12}$ And while these counterexamples concern visual imagination, similar counterexamples arise for other forms of sensory imagination too (think of how one might confuse the characteristic calls of two birds in auditory imagination).

Bad introduction and bad memory cases don't show that it is never the case that when $S$ intends to imagine $N$ and acts on that intention, the result is that $S$ imagines $N$. In fact we do think that the intentionalist's schema typically provides a correct characterization of how our intentional imaginings play out: that is, typically when one acts on the intention to imagine $N$ one ends up imagining $N$ as a result. However, we have shown that the schema fails in at least two kinds of cases. First, it fails when, prior to intending to imagine $N$, one was introduced to $N^{\prime}$ as $N$ and is never corrected (as in bad introduction cases). Second, it fails when, prior to intending to imagine $N$, one confuses $N$ and $N^{\prime}$ in one's memory (bad memory cases). In such cases intending to imagine $N$ and acting on that intention will instead result in one's imagining $N^{\prime}$.

So far our discussion has looked at subjects who intend to imagine $N$, where " $N$ " is a proper name. But the same kinds of counterexamples arise when proper names do not feature in subjects' intentions to imagine. Consider a subject who intends to imagine a plate of penne. Here the intention to imagine is an intention to imagine an $F$, where " $F$ " is a description of an object. Specifically consider the following case. Suppose your friend is introducing you to different types of pasta. She points to a plate of spaghetti and says, "That's penne", and you believe your friend. You later act on an intention to imagine a plate of penne, but your mental image resembles a plate of spaghetti because it traces back to your experience of seeing

\footnotetext{
${ }^{12}$ Comparison to the debate about how pictures represent may be instructive here, as Daniel Cavedon-Taylor (p. c.) pointed out to us. Hyman (2006: 137) briefly suggests that views about how pictures represent that lean heavily on the artist's intentions about what is represented face counterexamples. Thus, for example, according to Hyman, an artist may intend to depict a larch but only depict a spruce instead (although Hyman does not explain how such cases can arise).
} 
spaghetti. Despite your intention to imagine a plate of penne, you would have imagined a plate of the pasta which you incorrectly think is penne, but which is in fact spaghetti. (We could also easily generate a bad memory case in which you originally see both kinds of pasta and identify them correctly, but later mix up your memories.) Names in imagination ascriptions therefore play no essential role in generating bad introduction and bad memory counterexamples to intentionalism.

\section{Mistakes about what one is imagining}

So far we have raised counterexamples to intentionalism about sensory imagination. In Section 1 we alluded to another widespread view in the philosophy of imagination, which is closely associated with intentionalism. According to it, one cannot be mistaken about what one is imagining. ${ }^{13}$ In this section we argue that the same cases that refute intentionalism also refute this view.

The view that one cannot be mistaken about what one is imagining can be traced back to Sartre and Wittgenstein. Sartre takes it to capture a feature of the imagination which distinguishes it from sense perception:

When I say, 'the object I perceive is a cube', I make an hypothesis that I may have to reject at the close of my perceptions. When I say, 'the object of which I have an image at this moment is a cube', my judgment is final: it is absolutely certain that the object of my image is a cube (Sartre 1940/2004: 7).

Wittgenstein also seems to endorse the view when he claims that no amount of questioning should cause one to doubt one's beliefs about what one is imagining:

Someone says, he imagines King's College on fire. We ask him: 'How do you know that it's King's College you imagine on fire? Couldn't it be a different

\footnotetext{
${ }^{13}$ A more charitable way of formulating the view might appeal to Williamson's (2000: ch. 4) notion of luminosity. The view would then be that imaginings are "luminous": whenever you imagine $N$, you're in a position to know that you're imagining $N$. Preferring this formulation is of no help here though, since our cases also show that imaginings are not luminous. Some proponents of the view in the main text also state the view as the claim that our beliefs about what we are imagining are "immune to error through misidentification" (see Dorsch 2012: 94-6 and Perrin 2016: 48-9). We avoid this terminology since it is open to so many interpretations (see Morgan 2019 for a discussion that lays out a range of options).
} 
building, very much like it? In fact, is your imagination so absolutely exact that there might not be a dozen buildings whose representation your image could be?'And still you say: 'There's no doubt I imagine King's College and no other building'. (Wittgenstein 1958: 39).

Various philosophers have since followed Sartre and Wittgenstein in adopting this view and, much like intentionalism itself, it often features as an assumption in contemporary philosophy of imagination that has seemed too obvious to require defense. ${ }^{14}$

As mentioned in Section 1, the view that one cannot be mistaken about what one is imagining is closely connected to intentionalism. In particular intentionalism is sometimes used to explain why, allegedly, we can't be mistaken about what we're imagining. ${ }^{15}$ This explanation assumes that we have special access to our own intentions about what to imagine in the following sense: whenever one intends to imagine $N$ one can know this to be the case by reflection alone. It also assumes that when one acts on an intention to imagine $N$, and reflects on what one has imagined as a result, one will come to believe oneself to have imagined $N$. Under these assumptions, if intentionalism is true-i.e., we in fact always do end up imagining what we intend to imagine - then our beliefs about what we're imagining can never be false (at least provided the imagining is intentional).

We have already argued against intentionalism, so we don't think this argument for itlike any argument for intentionalism — can succeed. Still, it's worth considering the plausibility of the view that one cannot be mistaken about what one is imagining in its own right. ${ }^{16}$ When we do, we see that we can easily modify our earlier counterexamples to intentionalism so that

\footnotetext{
${ }^{14}$ See especially Tidman 1994: 301, McGinn 2004: 30-1, Kung 2010: 626, 2016: 95, Dorsch 2012: 94-6, Perrin 2016: 48-9, and Kind 2019: 167. There has been some notable dissent however. Walton (1990: 2930) sketches counterexamples that resemble ours. And Peacocke (1985: 27) resists the view to a certain extent for similar reasons: he argues that there is a sense in which one can be mistaken about a mental image's content, though one cannot be mistaken about the stipulative content of one's imagining (which he calls "S-imagination"). Finally cases discussed in the literature about modal intuitions may serve as counterexamples. There van Inwagen (1998) and others propose cases where, in effect, someone believes herself to have imagined that $p$ but one has failed to do so. (For example: I might take myself to have imagined a zombie or a certain mathematical conjecture; that I have in fact done so is disputed by van Inwagen and others though.)

${ }^{15}$ See especially Ishiguro 1966: 162, McGinn 2004: 31, Dorsch 2012: 106, and Kind 2019: 167. For criticism of this line of argument, see Peacocke 1985: 26.

${ }^{16}$ In fact some authors endorse this view without discussing intentionalism. Sartre is an example (in the passage quoted in the main text). Kung $(2010,2016)$ and Perrin (2016) are recent examples.
} 
they work as counterexamples here, too. Recall College Introduction, in which your friend points to Trinity College and tells you that it is King's College. You then act on an intention to imagine King's College on fire, but you end up instead imagining the college to which your mental image's causal history traces back-i.e., you end up imagining Trinity College despite your intention to imagine King's College. It is easy enough to fill in the initial description of the case by stipulating that you also believe that you are imagining King's College. Doing so doesn't alter the intuitive verdict that you fail to imagine King's College. The belief that you are imagining King's College is then mistaken. So, the view that one can't be mistaken about what one is imagining is false.

We can easily make parallel modifications to any of our cases in the last section by stipulating that you believe you imagined what you intended to imagine. The more general lesson here is this: we can generate a case in which one is mistaken about what one is imagining by adding the stipulation that one believes one is imagining what one intended to any case where one intends to imagine something but ends up imagining something else. ${ }^{17}$ The lesson applies to any case where the causal history of one's imagery has resulted in a failure to carry out one's imaginative intentions. So, besides interfering with intentions, the causal history of the imagery can also interfere with one's ability to form true beliefs about what one is imagining. ${ }^{18}$

\section{Sketch of a positive theory}

Intentionalism does not give the correct account of how imaginings get to be about what they are about, or so we aim to have shown. For all we have said, it may be that intentions are one ingredient which (often) play a role in determining what one's imaginings are about. However our counterexamples reveal something important that intentionalism leaves out: that a past mistake in identifying the object one now intends to imagine can get in the way of successfully

\footnotetext{
${ }^{17}$ No additional stipulation is needed if in general whenever one intends to imagine $N$, one believes one is imagining $N$. This is an instance of a more general schema according to which whenever $S$ intends to $A, S$ believes of herself that she is or will $A$, which some philosophers of action have found plausible (see Setiya 2018: $§ 5$ for overview).

${ }^{18} \mathrm{We}$ are leaving open whether there is a certain kind of imaginative content about which subjects can't be mistaken. For relevant discussion of de se imagining, see Recanati 2007: chs. 27-29.
} 
carrying out one's intention to imagine that object. In our cases a subject confuses another object for the object they now intend to imagine, either in their original experience of that object or in their memory of it.

So far our arguments against intentionalism have been supported largely by intuitions about bad introduction and bad memory cases. We now sketch a positive account of how many sensory imaginings get to be about what they are about, which explains how the causal history of our mental imagery can prevent us from imagining what we intended. According to our account, mental images - and consequently the sensory imaginings to which they belong ${ }^{19}$ by default represent whatever objects to which they causally trace back in experience, unless a subject intends or stipulates that the image be used to represent some other object. For this reason, what we intend to imagine is not purely a function of what we intend to imagine; the causal history of our mental imagery can also make a difference. ${ }^{20}$

To see how the account works, it's helpful to begin with an analogy to photographs. Suppose you take a photo of Trinity College, which represents that college because of its causal connection to it. Ordinarily, that photo will then continue to represent Trinity College - any time you retrieve it from your photo album, you will be retrieving a photo of Trinity College, even if you later forget what the image represents and start calling it "King's College." The photo continues to represent Trinity by default unless you intentionally use it to represent something else. Suppose, for example, that you are creating a collage of some fictional town. You cut out the image of Trinity College and paste it on your collage, thereby stipulating that it now represents a college in your fictional town. It's only once you do this that you override the photo's default representational content.

Intuitively mental imagery works something like this, too. Suppose you see Trinity College and retain a memory image of it. It seems that, by default, this image continues to

\footnotetext{
${ }^{19}$ Here and throughout this section we assume that mental images represent objects like King's College. We expect some readers to disagree, maintaining instead that imagistic content is purely qualitative. Which is true is not important for our purposes since we are primarily interested in what sensory imaginings represent overall. (Readers who disagree with us on this point should feel free to adapt our remarks about the content of mental imagery as they see fit.)

${ }^{20}$ We're not the first to claim that the causal history of a mental image is relevant for determining what an imagining is about. For suggestive remarks along these lines, see Peacocke (1985: 26-27) and Walton (1990: 29-30) in particular.
} 
represent Trinity whenever you consciously bring it to mind. You might intentionally recall this image, or it might pop into your head while mind-wandering or dreaming. In all these cases, the image simply represents the object to which it causally traces back in perception. Still, you can use the image to represent something else. For example, you might imagine some fictional town and use your image of Trinity College to represent a college in that town. When you do this, you intentionally use the image to represent that fictional college as part of your imagining. But it's not until you do this that you override the default case in which the image represents Trinity - in the absence of some kind of stipulation or intention to use the image some other way, we would not be tempted to say that the image, when it comes to your mind, represents anything other than Trinity.

In at least some cases, this idea seems to extend to intentionally using an image of one college to represent another, real college, as opposed to a fictional one. Suppose your friend tells you a story about her first time visiting King's College and you imagine this story as she tells it. If you've never seen King's College before but do know what Trinity College looks like, you might use a mental image tracing back to Trinity College as a stand-in for King's when carrying out your imagining. Your mental image represents King's College when you intentionally use it to do so. ${ }^{21}$

Consider now our College Introduction and College Memory cases. In these cases, you think you're imagining King's College when you bring to mind an image that causally traces back to an experience of seeing Trinity. But the cognitive process you are performing is not one of intentionally using the image to represent King's College, nor of stipulating that the image now represents King's. Instead, you are simply trying to bring to mind an image of a college. This is analogous to the case in which you retrieve a photo that represents Trinity but you mistakenly label it "King's College": the fact that you mistakenly label it as such does not change what the image by default represents given its causal history. Of course, you do intend to imagine King's College rather than Trinity; however, you do not intend to use an image

\footnotetext{
${ }^{21} \mathrm{We}$ expect there to be limits on our ability to use an image of one object to represent another in the imagination, however. For example, you may not be able to use an image tracing back to a visual experience of the Eiffel Tower to represent the White House no matter how hard you try to "override" the initial stipulation that it represents the Eiffel Tower. (Although arguably it is possible in recherché cases like one where you intend to imagine that the White House looks just like the Eiffel Tower.)
} 
originally of Trinity to represent King's. Something like the latter seems to be required in order to override the default case in which the image represents Trinity. ${ }^{22}$

Various intentions might serve to override the default content of the sensory imagining. As just suggested, you might form an intention to override the original content. However, this requires that you grasp the fact that your mental image originally represented Trinity College and we don't think this is required in order to override the default content. Your intention need not make any reference to the image's original content. You could also bring to mind an image which you know was originally of Trinity yet simply intend to use the image currently before your mind to represent King's. Or you could even forget which college your image originally represented but nevertheless bring it to mind and stipulate that it now represents King's College (compare a case in which you forget which college a photograph represents but you later use it in a collage to represent King's College).

It might be tempting to think our account implies that the subjects in College Introduction and College Memory imagine King's College after all —isn't it true that these subjects intend to use their mental images to represent King's College? ${ }^{23}$ This misconstrues the relevant intentions in our cases. Our subjects simply intend to imagine King's College and act on this intention by bringing to mind an image which they already take to be of King's College. So, their intention is not to stipulatively use their mental images to represent King's College. The mere intention to imagine King's College isn't an intention to use a particular mental image to represent some particular object, which is an intention with a more complex content than the one on which our subjects act.

In general, it's clear that our mental images often simply represent objects to which they causally trace back in perception. Other times, though, they represent objects we have never even perceived before - one can use an image of a college one saw in the past to represent a fictional college, or one can even do so by combining parts of different colleges one saw in the

\footnotetext{
${ }^{22}$ We don't mean to imply that one inevitably succeeds in carrying out such overriding intentions. You might fail to carry out your intention to use an image of Trinity College to represent King's as follows. A friend wrongly introduced Queens' College to you as Trinity once; as a result, your memory of the college you take to be Trinity is actually a memory of Queens' College. When you intend to use an image of Trinity to represent King's presumably you will fail because you bring to mind an image causally tracing back to Queens' rather than Trinity. Thanks to an anonymous reviewer for drawing our attention to this case.

${ }^{23}$ Thanks to an anonymous reviewer and to Daniel Stoljar for pressing us on this point.
} 
past. We can also use mental images tracing back to a single perceptual experience to represent multiple different objects, as when one uses an image tracing back to King's College to represent either King's or some fictional college. An account of how sensory imaginings get their contents should be able to explain the differences between all these cases. The theory we have just sketched does this: when an image causally traces back to an object in perception, it will represent that object by default, and we can override this constraint by intentionally using the image to represent something else. ${ }^{24}$

We mean to remain neutral in this section about whether imaginings always have stipulated content. Some theorists hold that all sensory imaginings involve two kinds of content: their qualitative, phenomenal content and the propositional content which one "stipulates" or "assigns" to a mental image, which always partly determines what that image is about. ${ }^{25}$ If one accepts such a view, our arguments in this section can accommodate it. Our view would then be that imaginings come with a default stipulation which assigns them the content to which they causally trace back in perception, unless we stipulate that they represent otherwise. This seems plausible given that, again, very automatic imaginings generally seem to represent the object to which they causally trace back, unless we re-stipulate their content.

Alternatively, it may be that there's no stipulated content to our imaginings in the class of "default" cases and that stipulated content only comes into the picture once we make a stipulation that overrides default content. This would still accommodate one of the primary motivations for which theorists posit stipulated content in the first place: to explain how qualitatively identical mental images can represent different objects. A view that says we can change the default, non-stipulated content of an imagining by stipulating new content still explains how this is possible.

\footnotetext{
${ }^{24}$ Our account is silent about at least one kind of case. Imaginings don't always draw on images stored from particular past experiences but instead sometimes draw on general background knowledge about the world. For example you might intend to imagine some college (whether real or fictional) and do so based on your general knowledge of English architecture. We take no stance on how content is determined in these cases, since we're focused on counterexamples to intentionalism in which the content of an image is anchored in a past experience of an object.

${ }^{25}$ For views of this sort, see Fodor 1975: 199-200, Peacocke 1985: 25-6, and especially Kung 2010, 2016 and Langland-Hassan 2020: ch. 4.
} 
Our account in this section improves on the resemblance-based view we described in Section 2. As we explained above, the resemblance-based view seems inadequate since resemblance isn't sufficient for determining the content of sensory imaginings. Furthermore, resemblance doesn't even seem to be necessary: it seems that you can imagine King's College based on a memory of it even if you've forgotten certain aspects of what it looks like and misimagine them, such as the colour of the building's roof or the shape of its windows. We haven't put resemblance-based constraints on the contents of imagination so we avoid these problems.

Our account thus respects one of the original motivations behind intentionalism, which was to find an alternative to the resemblance-based view. But it's a better alternative than intentionalism because it respects intuitions about bad introduction and bad memory cases. It also improves on intentionalism by explaining a wider range of cases. Intentionalism only covers cases in which one intends to imagine some content, whereas our view also covers cases of unintentional imagining.

\section{Objections and Replies}

We now turn to considering objections to the alternative to intentionalism we have just sketched.

First one might object that we have misconstrued the intention that actually causes the imagining in cases like College Introduction. We described that case as one in which you act on an intention to imagine King's College but fail because you were originally introduced to Trinity College as King's. But one might construe the intention which causes your imagining as an intention to imagine the building your friend introduced to you as King's College. Perhaps you try to imagine King's College only indirectly, by means of forming and acting on this more complex intention.

We think there are possible cases in which one forms intentions like this, although we don't think this is the most natural reading of our original case. Still, if one is inclined to accept this alternative construal, we can modify the original case to make it clearer that the intention which triggers the imagining is merely an intention to imagine King's College. Suppose again that, after your friend introduces you to Trinity College as King's, you retain a memory image with the label "King's College." However, you eventually forget the circumstances under 
which you encountered this building: you forget who introduced it to you, the context in which it was introduced, etc. Then, you intend to imagine King's College on fire and do so by drawing on this memory image. Because you've completely forgotten the context in which you were introduced to this building as King's College, it can't be that your intention was to imagine the building that was introduced to you as King's College. But because your mental image traces back to your perception of Trinity College, it again seems that you imagine Trinity College. ${ }^{26}$

Another possible objection to our account of bad introduction and bad memory cases tries to diagnose what has gone wrong in these cases in another way. Rather than appealing to the causal history of an image, it appeals to the fact that the imaginer simply has many mistaken beliefs about the object she intends to imagine. In College Introduction, for example, the subject has many false beliefs about what King's College looks like - might we trace her failure to imagine King's College back to the fact that she has all these false beliefs rather than back to her misleading introduction to Trinity College?

This seems like the wrong explanation for her failure because there are many cases in which subjects have mistaken beliefs about the objects they intend to imagine which don't pose a problem for intentionalism. If one accurately identified King's College in the past but never got it mixed up with Trinity College or any other object, it is plausible that one can later visualize King's College even if one doesn't remember what King's College looks like. It is therefore not merely having many mistaken beliefs about an object that prevents one from imagining it when one intends to.

A third objection to our account of bad introduction and bad memory cases again appeals to the false beliefs our subjects have about King's College but denies that they fail to imagine King's College. When we have false beliefs about what an object looks like, it's possible to accidentally mis-imagine it in the sense that, unbeknownst to us, we imagine it looking differently than it actually does. One might try to explain away the intuition that our subjects fail to imagine King's College by claiming that they merely mis-imagine King's College as

\footnotetext{
${ }^{26}$ One might respond that even in our revised case the subject does not intend to imagine King's College. Perhaps, instead, the subject merely intends to imagine the building she takes to be King's College (or the building she remembers as King's College). We think it implausible that whenever a subject takes an attitude towards an object $N$ she does so under a description such as "the object I take to be $N$ ". Likewise, the same goes for intentions to imagine objects: one can simply have an intention to imagine $N$ without ever thinking about $N$ under such a description (or indeed any description at all).
} 
looking like Trinity College. Perhaps we're intuitively inclined to say they failed to imagine King's College altogether when in fact they merely radically mis-imagined it?

This objection glosses over an intuitively compelling distinction which our own account of these cases respects. We can distinguish two kinds of cases in which you have false beliefs about the object which you intend to imagine. In the first, your mental image does in fact trace back to an experience of seeing King's College, but you have various false beliefs about King's College because you have forgotten what it looks like. In the second, you have false beliefs about King's College because you don't realize your mental image actually traces back to an occasion on which you saw a distinct object, Trinity College. The explanation for your false beliefs is different in these two kinds of cases. And intuitively they differ when it comes to your ability to imagine what you intend to imagine: in the first kind of case, it seems that you still carry out your intention to imagine King's College, while in the second kind of case it seems that you fail to carry out your intention.

Rather than lumping these cases together and trying to explain away our intuitions about the second kind of case, the positive theory we've sketched in this paper allows us to maintain a principled difference between them. We have argued that mental images by default represent the object to which they causally trace back unless one intentionally uses the mental image to represent another object. This theory predicts the intuitive verdicts about each kind of falsebelief case: when you have false beliefs but your mental image nevertheless traces back to the object you intend to imagine, you succeed in carrying out your intention; by contrast, when you have false beliefs because your mental image traces back to another object, you fail to carry out your intention.

Finally, we close by anticipating an objection from intentionalists. Intentionalists might insist that even in cases like College Introduction and College Memory it seems (at least to them) that the subjects have succeeded in imagining King's College. To the extent that there is a robust pre-theoretic King's College intuition at all, we think an explanation of it is available to us. 
To see how, we'll start by drawing an analogy with Kripke's (1977) distinction between "semantic reference" and "speaker's reference." 27 For Kripke the semantic referent of a name is the object it refers to by the conventions of the language one is speaking, whereas the speaker's referent of a name is the "object which a speaker wishes to talk about, on a given occasion, and believes fulfills the conditions for being the semantic referent of the designator" (1977: 264). Kripke illustrates how the two can come apart with a case in which two people see Smith in the distance raking leaves but mistake him for Jones. One asks, "What is Jones doing?" to which the other replies, "Raking the leaves." While the semantic referent of "Jones" is Jones, the speaker's referent of "Jones" in this context is Smith. The latter, pragmatic notion allows us to capture a sense in which the pair conversing have managed to refer to Smith and said something true about him in spite of their confusion.

Kripke's distinction doesn't apply to our cases since it concerns language rather than thought. However, it seems we can draw a similar distinction at the level of thought (and imagery in particular). We might distinguish the "thinker's referent" of a mental image from its semantic referent: the former is the object which a thinker wishes to imagine, on a given occasion, and believes fulfils the conditions for being the semantic referent of the image. In our College Introduction and College Memory cases, the thinker's referent of the image is King's College even though its semantic referent is (unbeknownst to the imaginer) Trinity College. ${ }^{28}$

If we help ourselves to such a distinction, then perhaps the reason intentionalism seemed plausible in the first place is that proponents of the view were picking up on intuitions about a kind of reference-specifically, thinker's reference. Furthermore, we can concede to the intentionalist that there is a genuine sense, the thinker's reference sense, in which our subjects represent King's College with their mental imagery. When it comes to the more standard notion

\footnotetext{
${ }^{27}$ Thanks to an anonymous reviewer for encouraging us to develop this analogy.

${ }^{28}$ Variants on our counterexamples to intentionalism that use definite descriptions instead of names are also possible (pointing at Trinity, your friend might say, "That's the college Alan Turing attended as an undergraduate" when in fact Turing's college was King's). When you act on the intention to imagine Turing's college on fire, presumably there is a sense in which you can succeed when you conjure up an image that traces back to your experience of seeing Trinity College and imagine it on fire. Again we might identify the thinker's referent of the image with Turing's college (i.e. King's) even though the semantic referent of the image is Trinity College. (We mention such cases because they more closely resemble those found in Donnellan 1966, which inspired Kripke's original distinction.)
} 
of semantic reference on which the notion of thinker's reference is parasitic, however, intentionalism is false.

\section{Conclusion}

This paper argued against intentionalism about the imagination, or the common view that what one imagines always matches one's intentions about what to imagine. Counterexamples to intentionalism can arise in one of two ways, as our "bad introduction" and "bad memory" cases demonstrate. In both kinds of cases an imaginer acts on an intention to imagine one thing yet ends up imagining something else. These cases also serve as counterexamples to another widespread view about the imagination, which is closely associated with intentionalism: that one cannot be mistaken about what one is imagining. ${ }^{29}$ It thus turns out that both views are wrong for some of the same reasons. Since these views serve as assumptions in various arguments by contemporary philosophers of imagination, the implications of rejecting them are potentially wide-ranging. ${ }^{30}$ While we do have a great deal of freedom in imagining what we choose, our aim here has been to expose some limits on this freedom. ${ }^{31}$

Following the lead of intentionalists, our focus in this paper has been on sensory imagination. One question our discussion might prompt is whether intentionalism can be

\footnotetext{
${ }^{29}$ Arguably our cases also threaten intentionalism about supposition provided we assume supposition is a kind of imagination, as some do (e.g. Currie and Ravenscroft 2002: 33-38). This is because, if supposition is a kind of imagination, then we should expect many acts of supposition to count as cases of "sensory imagining" on our construal: that is, they are imaginings that involve mental imagery. Without altering the setup of our cases too much (if at all), it seems we can describe the subjects in them as acting on an intention to suppose that King's College is on fire and failing, instead only managing to suppose that Trinity College is on fire.

${ }^{30}$ Intentionalism features in debates about the possibility of learning from the imagination (Langland-Hassan 2016, Balcerak Jackson 2018), the possibility of visualizing without imagining an experience (Noordhof 2002), and property dualism in the philosophy of mind (Kind 2019). The view that we can't be mistaken about what we imagine features in the epistemology of modality (Tidman 1994, Kind 2016) and Kung (2010, 2016) uses it to motivate his account of the imagination. Both views crop up in debates about how imagination differs from other mental faculties, especially perception and memory (Sartre 1940/2004, Wittgenstein 1980, McGinn 2004, Langland-Hassan 2016, Balcerak Jackson 2018, Kind 2019), and in arguments for "actuality-oriented imagination" being a cognitive capacity distinct from other kinds of imagination (Munro forthcoming).

${ }^{31}$ As in the introduction, here we follow intentionalists in linking the view to the freedom to choose what we imagine (see especially Langland-Hassan 2016, Balcerak Jackson 2018: 223). Several links may be possible, but the one we are assuming in the background here is simply this: if subjects can't always imagine $N$ by acting on an intention to imagine $N$, then they are not completely free to choose what they imagine.
} 
reworked as a view about non-sensory imagination instead. Imaginings do not seem to always involve mental imagery. ${ }^{32}$ Some theorists of imagination recognize a category of imaginings that behave like beliefs, and it looks like many of these "belief-like" imaginings do not involve mental imagery. ${ }^{33}$ For example, it seems we might imagine that Norway has the same GDP per capita as Turkey or that Donald Trump won the 2020 election without conjuring up any mental imagery whatsoever. Some of the intuitive motivation for intentionalism carries over to such imaginings - in particular, we have a great deal of freedom in choosing the contents of our non-sensory imaginings. More significantly, though, we can't object to intentionalism about non-sensory imagination by appealing to considerations about the causal history of mental images. ${ }^{34}$

We think intentionalism about non-sensory imagination may in fact suffer from similar counterexamples which, although they don't trade on the causal history of a mental image, still trade on the causal history of one's thoughts in a broader sense. Consider a case in which, as an undergraduate, you take a course in which you read a lot about the respective political and economic environments of Norway and Turkey. You form rich mental files about each country. However, in between the time you learn about these countries and your final exam, you get these two files mixed up: you associate the set of information that's true of Turkey with the label "Norway" and vice versa. On the exam is the following question: "Imagine that Norway didn't have any oil in its territory. Would there then be greater political will in Norway to join the EU?" You form and act on the intention to imagine a scenario in which Norway has no oil, in order to figure out its consequences. When you fill in the details of this imagined scenario,

\footnotetext{
${ }^{32}$ Although there is a longstanding tradition in the philosophy of imagination that reserves the word 'imagine' for mental states and processes that involve mental imagery (see e.g. Descartes 1984: 50-1). For recent discussion, see White 1990 and Kind 2001.

${ }^{33}$ Many but arguably not all: various theorists of imagination posit belief-like imaginings (or something similar) that have mental imagery as constituents (see especially Van Leeuwen 2014: 799 and LanglandHassan 2020: ch. 3). (We borrow the term "belief-like" for this kind of imagination from Currie and Ravenscroft 2002: 34.)

${ }^{34}$ This idea might seem especially plausible on one kind of view we alluded to in Section 4 which distinguishes two kinds of content for imaginings that involve imagery, the image itself and the assigned or stipulated content. Proponents of such a view might argue that our counterexamples to intentionalism involve subjects who go wrong only because there is a conflict between what their "image" component represents and the content they intend to assign to that image. This conflict obviously cannot arise for imaginings which only involve one "component"-namely, the non-sensory propositional one.
} 
you draw on information from the mental file mistakenly labelled "Norway", which contains information true of Turkey and not of Norway.

Here intentionalism implies that you imagined that Norway had no oil. Yet there's some intuitive pull towards thinking that you failed to imagine this and instead imagined that Turkey had no oil, because the country you take to be Norway is, in fact, Turkey. If this is right, then this case works much like College Memory above and would undermine intentionalism for similar reasons. At the same time, we acknowledge that intuitions about this case seem much less decisive than for our earlier cases. Perhaps you merely have many mistaken beliefs about Norway but still succeed in imagining it.

We thus leave open whether intentionalism can be reworked as a view about non-sensory imagination. If it can, it would constitute a surprising departure from standard formulations of intentionalism, which have characterized it as either a view about sensory imagination or imagination in general. Regardless, we hope to have cast serious doubt on intentionalism as it is standardly formulated. While intentions often determine what we imagine, intentionalism neglects the fact that the causal history of our mental imagery can also make a difference.

\section{References}

Balcerak Jackson, M. 2018. Justification by imagination. In F. Macpherson and F. Dorsch (eds.), Perceptual Imagination and Perceptual Memory, pp. 209-26. Oxford: Oxford University Press.

Currie, G. and I. Ravenscroft. 2002. Recreative Minds: Imagination in Philosophy and Psychology. Oxford: Oxford University Press.

Descartes, R. [1641-2, 1701] 1984. The Philosophical Writings of René Descartes, Volume 2, trans. J. Cottingham, R. Stoothoff, and D. Murdoch. Cambridge: Cambridge University Press.

Donnellan, K. S. 1966. Reference and definite descriptions. The Philosophical Review 75: 281-304.

Dorsch, F. 2012. The Unity of Imagining. Berlin: de Gruyter.

Fodor, J. 1975. The Language of Thought. New York: Crowell.

Hyman, J. 2006. The Objective Eye. Chicago: University of Chicago Press.

Ichikawa, J. 2009. Dreaming and imagination. Mind \& Language 24: 103-21.

Irving, Z. C. 2016. Mind-wandering is unguided attention. Philosophical Studies 173: 547-71.

Ishiguro, H. 1966. Imagination. In A. Montefiore and B. Williams (eds.), British Analytical Philosophy. London: Routledge.

Kind, A. 2001. Putting the image back in imagination. Philosophy and Phenomenological Research 62: $85-109$

- 2016. The snowman's imagination. American Philosophical Quarterly 53: 341-48.

- 2019. Mary's powers of imagination. In S. Coleman (ed.), The Knowledge Argument, pp. 161-79. Cambridge: Cambridge University Press.

Kind, A. and P. Kung, eds. Knowledge Through Imagination. Oxford: Oxford University Press.

Kripke, S. 1977. Speaker's reference and semantic reference. Midwest Studies in Philosophy 2: 255-76.

Kung, P. 2010. Imagining as a guide to possibility. Philosophy and Phenomenological Research 81: 62063. 
2016. You really do imagine it: Against error theories of imagination. Noûs 50: 90-120.

Langland-Hassan, P. 2016. On choosing what to imagine. In Kind and Kung 2016, pp. 61-84. 2020. Explaining Imagination. Oxford: Oxford University Press.

Martin, M. G. F. 2002. The transparency of experience. Mind \& Language 17: 376-425.

McGinn, C. 2004. Mindsight. Cambridge, MA: Harvard University Press.

Morgan, D. 2019. Thinking about the body as subject. Canadian Journal of Philosophy 49: 435-57.

Munro, D. 2021. Imagining the actual. Philosophers' Imprint 21: 1-21.

Noordhof, P. 2002. Imagining objects and imagining experiences. Mind \& Language 17: 426-55.

Peacocke, C. 1985. Imagination, experience, and possibility. In J. Foster and H. Robinson (eds.), Essays on Berkeley: A Tercentennial Celebration, pp. 19-35. Oxford: Clarendon Press.

Perrin, D. 2016. Asymmetries in subjective time. In K. Michaelian, S. B. Klein and K. K. Szpunar (eds.), Seeing the Future: Theoretical Perspectives on Future-Oriented Mental Time Travel, pp. 39-61. Oxford: Oxford University Press.

Recanati, F. 2007. Perspectival Thought: A Plea for (Moderate) Relativism. Oxford: Oxford University Press.

Sartre, J.-P. [1940] 2004. The Psychology of the Imagination. Translated by J. Webber. London: Routledge.

Searle, J. R. 1983. Intentionality: An Essay in the Philosophy of Mind. Cambridge: Cambridge University Press.

Setiya, K. 2018. Intention. In E. N. Zalta (ed.), The Stanford Encyclopedia of Philosophy. Fall 2018 edition.

Tidman, P. 1994. Conceivability as a test for possibility. American Philosophical Quarterly 31: 297-309.

Van Inwagen, P. 1998. Modal epistemology. Philosophical Studies 92: 67-84.

Van Leeuwen, N. 2014. The meanings of "imagine" part II: Attitude and action. Philosophy Compass 9: 791-802.

Walton, K. 1990. Mimesis as Make-Believe. Cambridge, MA: Harvard University Press.

White, A. R. 1990. The Language of Imagination. Oxford: Basil Blackwell.

Williamson, T. 2000. Knowledge and Its Limits. Oxford: Oxford University Press.

Wittgenstein, L. 1958. The Blue and Brown Books. Malden: Blackwell.

. 1980. Remarks on the Philosophy of Psychology: Volume II. Translated by C. G. Luckhardt and M. A. E. Aue. Edited by G. H. Von Wright and H. Nyman. Oxford: Blackwell. 